Pig Housing and the Environment

Occasional Publication No. 11-British Society of Animal Production 1987

edited by A. T. Smith and T. L. J. Lawrence

\title{
THE BEHAVIOUR OF DRY SOWS IN STRAW YARDS
}

\author{
R. H. R. JONES and A. M. PETCHEY \\ Scottish Farm Buildings Investigation Unit, Craibstone, Bucksburn, Aberdeen AB2 $9 T R$
}

\section{INTRODUCTION}

$\mathbf{I}^{\mathbf{n}}$ ntensive pig production systems are necessary for farmers to minimize production costs and to remain competitive. Recently, public concern for the welfare of farm animals has increased. The basic welfare requirements of pigs are a husbandry system appropriate to the health and so far as practicable, the behavioural needs of the animals together with a high standard of stockmanship. Research into the levels of productivity, the incidence of skin lesions, abrasions and injuries together with an evaluation of comfort, contentment and the good health of the pig should help to create a wider recognition of the pigs' needs and lead to more welfare-orientated production systems. The report of the House of Commons (1981) Agriculture Committee noted the 'obvious attractions' of keeping large groups of sows in straw yards but also the problem of aggression between sows. The report also recognized that in these circumstances there was fighting and bullying and the resultant nasty injuries could lead to serious losses. The main advantages of straw yards are that the sows have freedom to exercise and more opportunity to express their normal behaviours. There is a lack of information about the behaviour of dry sows in straw courts. These data are required to provide an appreciation of the nature and type of aggression whilst clarifying the expected level of other behaviours. The development of husbandry techniques and the design of straw yards which both minimize aggression and allow other behaviours to be expressed freely will be essential as it becomes necessary for the industry to adopt this type of dry-sow housing.

\section{MATERIAL AND METHODS}

The behaviour of two small groups of dry sows on each of four farms was determined. Two farms housed sows in a straw yard where they were floor fed and the other two farms fed the sows in stalls. Each group of sows was recorded for a $24 \mathrm{~h}$ period on three occasions; day 1, day 5 and in early pregnancy (mean $=42.7$ days; range 21 to 71 days). A National Panasonic video camera fitted with an $8.5-\mathrm{mm}$ auto iris lens was positioned above the pen.
Individual sows were clearly identified with a marker spray; the whole group was filmed simultaneously. In the analysis of the video tapes, three specific behavioural patterns were abstracted: general activity, rooting and aggression.

General activity was monitored every $5 \mathrm{~min}$ throughout the $24 \mathrm{~h}$ counting (on the minute) the number of sows which were active and not active. 'Active' states included standing and moving, whilst 'not active' states included sitting, dog sitting and lying. Rooting activities was sampled for the first $20 \mathrm{~min}$ of every hour. Rooting incidents which started in the sample period were followed until they ceased.

Incidents of aggression throughout the 24-h periods were recorded. Incidences were categorized as either a single lunge, a multiple lunge, a multiple lunge and chase or as sexual behaviour. Sexual behaviour and mounting occurred almost wholly on day 5 and have not been considered in this report. A record was kept of the identity of the attacking pig, its victim and the position within the pen where the incident occurred (water bowl, feeder/feeding, lying or general area).

Data were collected on two groups of six sows on three farms. On the fourth farm there were eight sows in the first group and seven in the second. The data for these two groups were scaled by factors of 0.75 and 0.875 respectively. As this data confounds feeder type and farm there are profound limitations to its statistical treatment. Nevertheless, it provides an opportunity to examine in more detail two dry-sow housing systems and assess some of their differences. In an analysis of variance, the degrees of freedom were allocated as follows:

$\begin{array}{lr}\text { Source } & \text { d.f. } \\ \text { Feeder type } & 1 \\ \text { Day } & 2 \\ \text { Feeder } \times \text { farm } & 2 \\ \text { Feeder } \times \text { day } & 2 \\ \text { Feeder } \times \text { farm } \times \text { day } & 4 \\ \text { Residual } & 12 \\ \text { Total } & 23\end{array}$




\section{RESULTS}

As expected there was more general activity (standing and moving) on day 1 than either on day 5 or in early pregnancy and during the first $4 \mathrm{~h}$ after mixing (day 1 ) general activity declined. This period was significantly greater than the activity registered in the first $4 \mathrm{~h}$ of recording on days 5 or day ' 42 ' (see Table 1).

Activity was at a maximum on all 3 days from 08.00 to $09.00 \mathrm{~h}$ and at a minimum from midnight to $03.00 \mathrm{~h}$. The level of general activity on day 5 was markedly less than day 1 and more similar to day ' 42 ' but the pattern was

TABLE 1

General activity of sows in groups of six

$\overbrace{1 \quad 5 \quad 422^{\prime}}^{\text {Day }}$ s.e.d. Significance

Mean activity

$\begin{array}{llllll}\quad \text { (daily) } & 2.05 & 1.64 & 1.75 & 0.291 & \\ \text { 1st h } & 5.09 & 2.40 & 2.60 & 0.647 & * * \\ \text { 2nd h } & 4.26 & 1.42 & 2.36 & 0.692 & * * \\ \text { 3rd h } & 3.67 & 2.19 & 1.85 & 0.771 & * \\ \text { 4th h } & 3.90 & 1.31 & 2.76 & 0.831 & *\end{array}$

TABLE 2

Agnostic encounters on two dry-sow housing systems

Sow

feeder Floor-fed

system system s.e.d. Significance

Total incidents

$\begin{array}{lccll}\quad \text { (daily) } & 13.4 & 22.2 & 3.91 & * \\ \begin{array}{l}\text { Lunge } \\ \begin{array}{l}\text { Multiple lunge } \\ \text { Lunge and }\end{array}\end{array} & 3.20 & 10.80 & 2.82 & * \\ \text { chase } & 6.17 & 5.29 & 0.901 & \\ & & 6.07 & 1.706 & \end{array}$

TABLE 3

Agonistic encounters within groups of sows after weaning

$\overbrace{1 \quad 5}^{\text {Day }}$ '42' s.e.d. Significance

Total incidents

$\begin{array}{lccccc}\quad \text { (daily) } & 29.0 & 15.7 & 8.7 & 4.79 & * * \\ \begin{array}{l}\text { Lunge } \\ \text { Multiple lunge }\end{array} & 9.80 & 5.90 & 5.30 & 3.45 & \\ \begin{array}{l}\text { Lunge and } \\ \text { chase }\end{array} & 13.03 & 4.72 & 2.76 & 1.104 & * * \\ & & & & & \\ \end{array}$

slightly different. On day 5 , there was more activity by (oestrous sows) between 18.00 and $06.00 \mathrm{~h}$ and less activity from 12.00 to $14.00 \mathrm{~h}$.

In general the mixing of sows on day 1 prompted a high initial level of aggression which declined as they became more familiar with each other and their surroundings. On day 5 , aggressive acts were more erratic but associated with the characteristic behavioural traits of oestrus.

The number of major aggressive incidents (greater than $20 \mathrm{~s}$ duration) was significantly greater $(P<0.05)$ in the floor-fed system than the sow feeder system (Table 2). This difference was almost wholly attributable to a greater incidence of single lunge attacks although only $30 \%$ of this difference was increased aggression whilst feeding.

The number of major aggressive incidences declined from day 1 to day ' 42 ' $(P<0 \cdot 01)$ (Table 3). The multiple lunge and chase was the most frequent type of aggressive act on day 1 but the single lunge had become the most common aggressive act on days 5 and ' 42 ' when the levels of aggression were much lower.

Rooting activity was sampled by recording the sows' activity in the first $10 \mathrm{~min}$ of each hour. The number of rooting incidences decreased significantly from day 1 to day 5 and ' 42 '. The time spent rooting also decreased but was greater $(P<0.01)$ on day ' 42 '. This occurred because straw was added to the pens on more occasions on day ' 42 ' than on day 5 . Fresh straw initiated an increase in rooting behaviour. The floor-fed system showed both a significantly greater number of incidences $(P<0.05)$ and a greater amount of time spent rooting $(P<0.05)$ than the sow feeder system.

\section{DISCUSSION}

The diurnal activity of sows was clearly identified in this study and showed that sows spent on average, proportionately 0.69 to 0.73 of the day resting or asleep. Clearly, most aggressive and rooting activities took place when the sow was most active which broadly corresponded to the working day.

From day 1 to day ' 42 ' the area or place within the pen where aggresion took place changed dramaticaly. The most common position on day 1 being the 'pen' in general, on day 5 the lying area and on day ' 42 ' the feeder. This was consistent with the sows being preoccupied with establishing a social hierarchy on day 1 and then changing from inter-pig competition, where the resource was not clearly identified, to the lying area when there was oestrous activity and finally in a stable group to competition largely for food. The severity of the agonistic encounters did decrease with time. The multiple lunge and chase predominating on day 1 but the single lunge on day ' 42 '. Agonistic behaviour was significantly greater for the floor-fed system than those groups provided with a feeder. Sow feeders increase the capital costs associated with maintaining a sow herd and 
their benefits need to be clearly appreciated. Although they reduce major incidents of aggression proportionately by $0 \cdot 39$, and much of this difference can be attributed to fewer single lunges at feeding time (i.e. than floor-fed sows), a substantial amount of aggression still occurred in the sow-feeder system. Further work should look at husbandry techniques and changes in pen design or equipment which would minimize agonistic encounters of dry sows whilst allowing them the welfare benefits of social groups and an environment enriched with straw which allows them to express their natural rooting behaviour. 